ISSN 1027-5495. Functional Materials, 25, No.2 (2018), p. 319-328

\title{
Thermodynamic and adhesive parameters of nanolayers in the system "metal-dielectric"
}

\author{
V. M. Yuzevych ${ }^{1}$, B. P. Koman ${ }^{2}$, R. M. Dzhala ${ }^{1}$ \\ ${ }^{1}$ G. Karpenko Physicomechanical Institute National Academy of Sciences \\ of Ukraine, 5, Naukova Str., 79060 Lviv, Ukraine \\ ${ }^{2}$ I.Franko Lviv National University, faculty of electronics and computer \\ technologies, Dragomanova Str., 50, 79005 Lviv, Ukraine,
}

\section{Received September 05, 2017}

\begin{abstract}
Evaluation technique of thermodynamic and adhesive parameters of interphase nanolayers in "metal - insulator" was developed by use of macroscopic methods of surface physics and thermodynamics methods of nonequilibrium processes. Typical parameters of interfacial interactions (interfacial energy, tension, density of electric charges, specific electrocapacity, electrical components of interfacial energy) for metals $(\mathrm{Ag}, \mathrm{Au}, \mathrm{Cu}, \mathrm{Fe})$ at $\mathrm{Al}_{2} \mathrm{O}_{3}$ interphase were calculated. It was found that increment of dielectric layer $\left(\mathrm{Al}_{2} \mathrm{O}_{3}\right)$ surface tension which is accompanied with increasing of interfacial tensions and energies, electric component of the surface energy, specific surface charge of double electric layer and contact potential difference.

The developed technique can be used for evaluation of interfacial energy parameters of interaction between another physical nature composited pairs with taking into account the nature of the double electrical layer.

Keywords: dielectric, metal, double electric layer, energy of adhesive bonds, surface energy, hardness, electric capacity.

С применением макроскопических методов физики поверхности и термодинамики неравновесных процессов разработана методика оценки термодинамических и адгезионных параметров межфазных нанослоев - “металл - диэлектрик". Рассчитаны характерные параметры межфазового взаимодействия (межфазовые енергии, натяжения, плотности электрических зарядов, удельные электроемкости, электрическиесоставляющиемежфазовой энергии ) для металлов ( $\mathrm{Ag}, \mathrm{Au}, \mathrm{Cu}, \mathrm{Fe})$, граничащих с $\mathrm{Al}_{2} \mathrm{O}_{3}$. Установлено, что увеличение поверхностного натяжения диэлектрического слоя $\left(\mathrm{Al}_{2} \mathrm{O}_{3}\right)$ сопровождается увеличением межфазовых натяжений и энергий, электрической составляющей поверхностной энергии, удельного поверхностного заряда двойного электрического слоя и контактной разницы потенциалов. Предложенная методика может быть использована для оценки энергетических параметров межфразового взаимодействия композиционных пар другой физической природы с учетом природы двойного электрического слоя.
\end{abstract}

Термодинамічні та адгезійні параметри наношарів у системі "метал діелектрик”. В.М. Юзевич, Б.П Колан, Р.М.Джала.

Зі застосуванням макроскопічних методів фрізики поверхні та термодинаміки нерівноважних процесів розроблено методику оцінювання термодинамічних та адгезійних параметрів міждразових наношарів - “метал - діелектрик". Розраховано характерні параметри міжфазової взаємодії (міжфазові енергії, натяги, густини електричних зарядів, питомі електроемності, електричні складові міжфразової енергіï) для металів $(\mathrm{Ag}, \mathrm{Au}, \mathrm{Cu}$, $\mathrm{Fe}$ ), які межують з $\mathrm{Al}_{2} \mathrm{O}_{3}$. Встановлено, що збільшення поверхневого натягу діелектричного шару $\left(\mathrm{Al}_{2} \mathrm{O}_{3}\right)$ супроводжуеться зростанням міжфазових натягів та енергій, електричної складової поверхневої енергії, питомого поверхневого заряду подвійного електричного шару та контактної різниці потенціалів. Запропонована методика може бути використана для оцінювання енергетичних параметрів міжфразової взаємодії композиційних пар іншої фрізичної природи з урахуванням природи подвійного електричного шару. 


\section{Introduction}

Composite systems of "metal - oxide" are widely used as active and passive elements of micro- and nanoelectronics, elements of power sources, batteries capillary energy, corrosion-resistant materials and other [1,2]. Such systems have unique physical and mechanical properties and high chemical inertness. It is well-known example that aluminum oxide $\mathrm{Al}_{2} \mathrm{O}_{3}$ is used for metals corrosion protections and for increase of hardness characteristics of aerospace devices buildings [3]. To improve composite ceramics performance, the structures like " $\mathrm{Al}_{2} \mathrm{O}_{3}$ - powder" with higher strength parameter have found widespread use [4]. By variation of concentrations and powders types the composite materials with wide range of physical-mechanical and electrical parameters are fabricated.

To produce thermodynamically stable composite like "metal-oxide" with predictable physical and mechanical properties, deep understanding of the physical phenomenon at the interface of "nanolayer metal-oxide nanolayer" are required. However, due to complexity of the processes on the interface of two environments, their quantitative description is difficult. Usually, some empirical approach to describe the interfacial interaction between two materials are used. That is why, real electric charge situation on the "metal-oxide" interfacial is missed [5]. Some free surfaces parameters can be evaluated by density functional theory (DFT) [6,7]. DFT is rather complicated and cumbersome for practical use, its also uses additional theoretical assumptions which simplifies the calculating process, but reduces the accuracy and reliability of experiment data. In addition, DFT is not effective for interphase energy calculations. For macromodel description of "metal - dielectric" contacting surfaces, it is important to have reliable information about variation of their physical characteristics, which is included in the state equation and linked together the state parameters. Their values must properly meet the basic energy characteristics of the interphase layer - interfacial energy $\gamma_{m}$ and bounds adhesion energy $\gamma_{A d}$ [6-9]. The positive results of such approach for "metal-semiconductor" were shown in $[8,10]$.

The aim of the paper is to introduce the evaluation methods of thermodynamic and adhesive parameters (such as interphase energy $\gamma_{m}$, interphase tension $\sigma_{m}$, interfacial electric charge $\Omega$, electrocapacity of double electrical layer $C_{m}$, electrical component $\gamma_{m E}$ of interphase energy of interphase nanolayers in "metal-dielectric") by using macroscopic surface physics and thermodynamics of nonequilibrium pro- cesses. The proposed methodology should be tested for calculating the typical parameters of the interfacial interaction in $(\mathrm{Ag}, \mathrm{Au}, \mathrm{Cu}, \mathrm{Fe})$ $\mathrm{Al}_{2} \mathrm{O}_{3}$. Variations in the interphase tension and energy, the electric component of the surface energy, the specific surface charge and contact potential difference (CPD) by varying the basic parameters of the dielectric layer should be found too.

\section{Theoretical background and calculation method}

\subsection{Physical-mathematical model and basic equation}

The model of interphase phenomenon between two materials is based on asumption of connections between mechano-electrical processes on the solid state surface [11]. Let us consider the interface between two medias: "metalinsulator" or "metal - inert gas environment". Metal and dielectric are multi-elemental continuum mediums. The following components are selected inside metal: ions of the basic substance (e.g., copper $\mathrm{Cu}^{++}$), conduction electrons, impurities, point defects; in dielectric - atoms of the basic substance that believe dipoles and characterize the bound electric charge, impurities, point defects. In inert gas environment the composition components are not considered. In the vicinity of the medium boundaries the separation of electric charges is observed. Double electric layer (DEL) is organized (nanolayer, which corresponds to "surface condenser") and an electric potential difference $\Delta \Psi_{m}$ is appear [7]. Let us take into acount only stationary situation of the contacting media as "metal - inert gas environment" (such as air), "dielectric-air" and "metal-insulator". The thiknees of the DEL layer $h$ in the "metal - inert gas environment" (physical vacuum) is around $0,4 \div 0,5 \mathrm{~nm}[6$, 9], and for the "metal - electrolyte" is around $10 \div 100 \mathrm{~nm}[12]$.

Surface tension (ST) $\sigma_{h}$ and surface energy (SE) $\gamma$, which are basic energy parameters of the DEL are proportional to each other and presented by the Herring-Shuttleworth relation (based on the multiple scenarios) [13-15]:

$$
\begin{gathered}
\left(\sigma_{h}\right)_{i j}=K_{R}\left(\gamma \times \delta_{i j}+\left(\frac{\partial \gamma}{\partial e_{i j}}\right)_{T}\right), \\
\sigma_{h}=K_{R}\left(\gamma+\left(\frac{\partial \gamma}{\partial e}\right)_{T}\right), \\
\sigma_{h}=K_{R}\left(\gamma+S_{b}\left(\frac{\partial \gamma}{\partial S_{b}}\right)_{T}\right), \\
K_{R}=1 \frac{N \cdot m^{2}}{m \cdot J}
\end{gathered}
$$


where $S_{b}$ is the body surface area; $\frac{\partial \gamma}{\partial S_{b}}$ is the expression of change characteristic at the surface energy $\gamma$ during deformation (because, the derivative by surface area $S_{b}$ at a constant temperature $\mathrm{T}$ is deformation); $K_{R}$ is the parameter of dimensions matching [13-16]; $\delta_{i j}$ is the Kronecker symbol; $e_{i j}$ are components of deformation tensor $e$ ( $i, j=1,2$ for two-dimensional surface phases in Cartesian coordinates $x, y$ ); $e$ is the first invariant of deformation tensor $(e=$ $\left.0,5 \times\left(e_{x x}+e_{y y}\right)\right) ; T$ is the Kelvin temperature.

The components of deformation tensor $\hat{e}$ with the displacement vector components $u$ in Cartesian coordinates $(x, y, \mathrm{z})$ are related by the equations $[17,18]$ :

$$
\begin{gathered}
\hat{e}=\text { Def } \vec{u}, \\
\left(e_{x x}=\frac{\partial u_{x}}{\partial x}, \quad e_{y y}=\frac{\partial u_{y}}{\partial y}, \quad e_{z z}=\frac{\partial u_{z}}{\partial z}\right), \\
\vec{u} \Rightarrow\left(u_{x}, u_{y}, u_{z}\right) .
\end{gathered}
$$

Deformation tensor $e$ with the components of stress tensor $\sigma$ are related by state equation that is constitutive equation it's generalized Hooke's law [8, 16, 17]:

$$
\begin{aligned}
& \sigma_{i j}= \\
& \left(\left(K-\frac{2}{3} G\right) e-\alpha_{t} K \cdot \Delta T-K\left(\beta \phi+\beta_{c k} c_{k}\right)\right) \delta_{i j}+ \\
& +2 G e_{i j}
\end{aligned}
$$

where $K$ is a bulk modulus; $\mathrm{G}$ is a shear modulus; $c_{k}$ is the variation of impurity $C_{k}$ concentration $(k=1,2, \ldots, n)\left(c_{k}=C_{k}-C_{k 0}\right) ; \Delta T=T-T_{0}$ is temperature variation; $\varphi=\Phi-\Phi$ is a deviation of the modified chemical potential of the conduction electrons (MCPCE); $\Phi_{0}$ is the value of metal MCPCE far from the surface, where the influence of DEL on conduction electron is not exhibited; $\beta$ is the electrostrictive coefficient of thermal expansion; at is the temperature coefficient of thermal expansion; $\beta_{\mathrm{ck}}$ is the concentration coefficient of thermal expansion. The classical Hooke's law (3) under conditions $\Delta T=0, \varphi=0, c_{k}=0$ is presented [17]. The conduction electrons in the metal and continuous positive background that simulates the lattice ions are considered similarly as in the works [6, 7]. The conduction electrons are related with chemical potential $M_{2}$. Since the redistribution at the boundaries in the vicinity of continuous positive background is negligible [5-7]) than the potential $M_{\mathrm{o}}$ is reasonable to modify as difference $M_{2}-M_{1}$ and renamed it as modified chemical potential of the conduction electrons (MCPCE). The MCPCE with the chemical po- tentials of conductive electrons $M_{2}$ and ion lattice $M_{1}$ are related to [19]:

$$
|\Phi|=\left(M_{2}-M_{1}\right) /\left(z_{2}-z_{1}\right),
$$

where $z_{2}$ and $z_{1}$ are electric charges per unit mass of conduction electrons and ions of the lattice basic substance (for example, for copper it's copper ions $\mathrm{Cu}^{++}$). The chemical potential of metal electronic subsystem $\mathrm{M}_{2}$ is defined in [7-9]. Equation (4) gives us the possibility by single parameter to consider information of the conduction electrons and the lattice of ions, which are simulated by continuous positive background.

Let us introduce $\Phi$ parameter for the well known Gibbs equation [19-22]:

$$
\begin{gathered}
d U=T d S+\frac{1}{\rho} \sum_{i, j=1}^{3} \sigma_{i j} \cdot d e_{i j}+\sum_{k=1}^{n} M_{k} \cdot d C_{k}, \\
d F=-S d T+\frac{1}{\rho} \sum_{i, j=1}^{3} \sigma_{i j} \cdot d e_{i j}+\sum_{k=1}^{n} M_{k} \cdot d C_{k},
\end{gathered}
$$

where $F$ is a density of free energy of continuous medium (calculated per unit mass); constant variables for: deformations $-e_{i,}, \sigma_{i} ;$ thermal conductivity $-T$ and entropy $-S$; diffusion - $C_{k}$ and chemical potential of impurities $M_{k}$; $d T=\Delta T=T-T_{0} ; k=1,2, \ldots n ; n$ is number of components (including chemical); $k=1$ is ion index of the basic substance; $k=3,4, \ldots, n$-2 are indexes of impurities; $k=n-1$ is indexes of point defects (vacancies); $k=n$ are index of the point defects (interstitial atoms).

Since $\sum_{k=1} C_{k}=1$ than equation (5) is modi-

$$
\begin{aligned}
d F_{*}= & -S d T+\frac{1}{\rho} \sum_{i, j=1}^{3} \sigma_{i j} \cdot d e_{i j}-\omega d \Phi+ \\
& +\sum_{k=3}^{n} M_{k} \cdot d C_{k}
\end{aligned} .
$$

In general the state equations are coming out from (6):

$$
\begin{aligned}
& \sigma_{i j}=\rho \cdot \partial F_{*} / \partial e_{i j}, \quad S=-\partial F_{*} / \partial T, \\
& M_{k}=\partial F_{*} / \partial C_{k}, \omega=\partial F_{*} / \partial \Phi=\partial F_{*} / \partial \phi
\end{aligned} .
$$

If $F_{*}$ expands into Taylor series by small parameters and leave only two (quadratic) members of expansion, than we will come to the linear state equation like (3) and both density electric charge equation $\omega$ and chemical potential of impurities $\mu_{\mathrm{c}}$ :

$$
\begin{gathered}
\omega_{V}=\rho \omega=\rho C_{\phi}\left(\phi-\gamma_{t} \cdot \Delta T\right)+\beta K e-\rho \eta_{c} c, \\
\mu_{c}=d_{c} c+d_{t} \cdot \Delta T+\beta_{c} K \frac{e}{\rho}-\eta_{c} \phi,
\end{gathered}
$$

where $C$ is electrocapacity; $\omega_{V}$ is density of electrical charge per unit volume, $\mathrm{C} / \mathrm{m}^{3} ; c_{3}=c$; 
$\mu_{c 3}=\mu_{\mathrm{c}} ; \gamma_{\mathrm{t}}, \eta_{\mathrm{c} 3}=\eta_{\mathrm{c}}, d_{\mathrm{c} 3}=d, d, \beta_{\mathrm{c} 3}=\beta_{\mathrm{c}}$ are physical parameters of the material (let's consider one type of impurities $\left(k=3, c_{3}=c\right)$ and take into account the symmetry factors $\eta_{c}$ in state equations (8), (9)).

We believe that the processes are isothermal $(\Delta T=0)$ and the impurities are absent $(k=1,2$; $c=0$ ) than equation (6) will transform in:

$$
d F_{*}=\frac{1}{\rho} \sum_{i, j=1}^{3} \sigma_{i j} \cdot d e_{i j}-\omega d \phi,
$$

The equation (10) meets two processes: redistribution of electric charges $\omega$ (DEL formation) and the appropriate mechanical stresses in the vicinity of the metal surface are generated.

For (10), the state equation (constitutive equations) which is coming out from (3) and (8) will take form:

$$
\begin{gathered}
\sigma_{i j}=\left(\left(K-\frac{2}{3} G\right) e-K \beta \phi\right) \delta_{i j}+2 G e_{i j}, \\
\omega_{V}=\rho \omega=\rho C_{\phi} \phi+\beta K e=k^{2} \varepsilon_{0} \phi+\beta K e, \\
k=\sqrt{\rho C_{\phi} / \varepsilon_{0}} .
\end{gathered}
$$

In this case electrostrictive parameter of thermal expansion is written:

$$
\beta=\left.\frac{3(1+v)}{E} \cdot \frac{\partial \omega}{\partial e}\right|_{\phi=c o n s t} .
$$

The redistribution of conduction electrons and generation of mechanical stresses will be described by two balance ratios - the equation of balance momentum (the the equation of equilibrium of deformable bodies) and equation that links electric field vector $\vec{E}$ with density electric charges $\omega$ (state parameters):

$$
\begin{aligned}
& \operatorname{Div} \hat{\sigma}+\rho \cdot \omega \cdot \vec{E}=0 ; \\
& \varepsilon_{0} \cdot \nabla \cdot \vec{E}=\rho \cdot \omega=\omega_{V},
\end{aligned}
$$

where $\varepsilon_{0}$ is the electric constant; $\rho \cdot \omega \cdot \vec{E}$ is ponderomotive force in the balance equation of local body element. The second equation (13) is one of the Maxwell's equations [16-21].

Let's us consider one- the dimensional case. Interface between two medias $\Gamma$ is $x=0, x>0$ is metal and $x<0$ is inert gas environment. Since the $x$-axis is perpendicular to the metal surface we have:

$$
E_{x}=-\frac{\partial \Psi}{\partial x}=-\frac{\partial \psi}{\partial x},
$$

where $\Psi$ is electrical potential and $\psi$ is it's deviation $\left(\psi=\Psi-\Psi_{0}\right)$.

When two materials with different physical and chemical nature is in contact, the contact potential difference between their occur. In this case, let's consider the components of the electrochemical potential. For metal and inert gas environment it can be written as [16-21]:

$$
\Phi+\Psi=\phi+\Phi_{0}+\psi+\Psi_{0}=\text { const }=0 .
$$

The electric field intensity (14) with (15) takes the form:

$$
E_{x}=\frac{\partial \Phi}{\partial x}=\frac{\partial \phi}{\partial x},
$$

We assume that $\Psi=0$ (zero level of electric potential is chosen arbitrarily, since the DEL electric field is potential (no vortex)) on the $\Gamma$ metal interface $(x=0)$. So for MCPCE the boundary condition will be:

$$
\phi=-\Phi_{0} .
$$

The second boundary condition on the $\Gamma$ metal interface is coming out from equilibrium equation (13) (the first equation) for the components of the stress tensor, which is directed perpendicularly to the surface of the media [16, 18, 19-21]:

$$
\sigma_{x x}=-\frac{\varepsilon_{0}}{2} \cdot\left(\frac{\partial \Psi}{\partial x}\right)^{2}=-\frac{\varepsilon_{0}}{2} \cdot\left(\frac{\partial \phi}{\partial x}\right)^{2} .
$$

The second expresion (13) (the equations of electrodynamics) with (12), (14) and (16) will be written (the Helmholtz equation):

$$
\Delta \phi=\rho \cdot C_{\phi} \cdot \phi / \varepsilon_{0},
$$

Let us analyze the physical nature of the processes of conduction electrons redistribution and mechanical stresses generation in the vicinity of the surface $x=0$. Let's in physical vacuume at time $\tau=0$ the $\Gamma(x=0)$ interface is created. At the first stage, on the vicinity of the $\Gamma$ interface of environments metal - inert gas (the physical vacuum)) the distribution of conduction electrons is occurred. The $\varphi=\varphi(x)$ is genereted as consistent with equation (19) and boundary conditiion (17). Than the equation for electrostatic potencial $\Psi$ is modified in to $\Phi$ potencial distibution problem. On the second stage, under equation of equilibrium (13) (the first one) and boundary condition (18) for distribution $\varphi=\varphi(x)$ at the vicinity of the $\Gamma$ interface the distribution of mechanical stress, in particular components of $\sigma_{x x}, \sigma_{y y}, \sigma_{z z}$ are obtained. Let's consider only one component of the displasments on $x$ direction $-u_{x}$ component. For one-dimensional case (the linear displacement) under (2), strain tensor components take the form $[14,17]$ :

$$
\begin{gathered}
e_{x x}=\frac{\partial u_{x}}{\partial x}, \quad e_{y y}=e_{z z}=0, \\
e=\frac{1}{3} e_{x x}=\frac{1}{3} \frac{\partial u_{x}}{\partial x}
\end{gathered}
$$

Equation (20) that is presented under ux displasments component substitute in the state equation (11), (12). The state equation substi- 
tute in the balance relations (13) and (19), with (16) we come to a system of two nonlinear equations of $\varphi$ and $u_{x}$ :

$$
\begin{gathered}
\frac{d}{d x}\left[\frac{1}{x^{2}} \frac{d}{d x}\left(x^{2} \cdot u_{x}\right)\right]= \\
\frac{3}{3 \cdot K+4 \cdot G} \cdot\left[\beta \cdot K \cdot \frac{d \phi}{d x}-\omega \cdot \frac{d \phi}{d x}\right], \\
\frac{d^{2} \phi}{d x^{2}}=\frac{\rho \cdot C_{\phi}}{\varepsilon_{0}} \cdot \phi=k^{2} \phi, \quad k=\sqrt{\frac{\rho \cdot C_{\phi}}{\varepsilon_{0}}},
\end{gathered}
$$

The system of two equations (21) and (22) is not linear because ponderomotive force $\rho \cdot \omega \cdot \vec{E}$ $(\omega \cdot d \phi / d x)$ is not linear. From (21) and (22) we get $\varphi(x)$ and displasment $u_{x}(x)$.

Because of $\omega \cdot d \phi / d x$ (21) is not linear then equations (21), (22) with boundary condition (17), (18) for evaluetion of potensial destribution $\varphi$ and mechanical stress $\sigma_{y,}, \sigma_{y y}\left(\sigma_{y y}=\sigma_{z z}\right)$ in the vicinity of the medias interface are soloved analytically under displacements $\left(u_{x}=u\right)$ by method of small parameter $b=\beta \cdot \Phi_{0}[23,24]$.

Four close expansions is obteined:

$$
\begin{aligned}
& u_{x}=u= \\
= & u_{0}+b \cdot u_{1}+(b)^{2} \cdot u_{2}+(b)^{3} \cdot u_{3}+(b)^{4} \cdot u_{4} \\
& \phi=\phi_{0}+b \cdot \phi_{1}+(b)^{2} \cdot \phi_{2}+(b)^{3} \cdot \phi_{3}+(b)^{4} \cdot \phi_{4}
\end{aligned}
$$

The displacement component $u$ and $\varphi$ are presented in the form of series by small parameter $b$. The system of equations (21), (22) with (17), (18), (23) and (24) for the metal area are soloved:

$$
\begin{gathered}
\phi\left(x, k, \Phi_{0}\right)=-\Phi_{Z} \cdot \exp (-k x) ; \\
\Phi_{Z}=\frac{q_{0} W_{e}}{2 \varepsilon_{0} k^{2}} \cdot\left(2-\exp \left(-k Z_{b}\right)\right) ; \\
\Phi_{0}=\frac{q_{0} W_{e}}{2 \varepsilon_{0} k^{2}} ; \\
\sigma_{x}=\sigma_{x}\left(x, b, k, \Phi_{0}\right) ; \quad \sigma_{y}=\sigma_{y}\left(x, b, k, \Phi_{0}\right),
\end{gathered}
$$

where $\sigma_{x}\left(x, \beta, k, \Phi_{0}\right)$ and $\sigma_{y}\left(x, \beta, k, \Phi_{0}\right)$ are cumbersome expressions, which were soloved by developed computer program;

$Z_{b}=\frac{3}{4 k_{F}}\left(\frac{\pi}{2}+\left(\frac{5 E_{V}}{3 E_{F}}-1\right) \arcsin \sqrt{\frac{3 E_{F}}{3 E_{F}+5 E_{V}}}-\sqrt{\frac{5 E_{V}}{3 E_{F}}}\right)$

is the displacement of double electric layer relative to solid state interface [25]; $E_{F}$ and $k_{F}$ are Fermi energy and Fermi wave vector respectively; $E_{V}$ is metal electron work function; $W_{e}$ is bulk density of conduction electrons far from the metal surface (at the distance of more than $30 \mathrm{~nm}), 1 / \mathrm{m}^{3} ; 1 / k$ is distance where MCPEC decreases in $e$ times.
The soloved equation of redistribution of electric charges and mechanical stress sufficiently good describes the physical situation on the interface of "metal-metal". These relations give us the possibility to evaluate the variation of energy parameters on the layers interface.

\subsection{The determination of physical}

\section{paramiters in equation of state for metal}

Let's take surface tension $\sigma_{h}$, surface energy (SE) $\gamma$, equilibrium condition of the surface layer and effective thickness $h$ of the surface layer in state equation for determination of metal physical parameters $\beta$ and $k$ (11), (12) $[6-8,10$, 26, 27]:

$$
\begin{gathered}
\int_{0}^{h} \sigma_{y y} d x=\sigma_{h}, \quad \sigma_{y y}=\sigma_{z z}, \\
\gamma_{e}+\xi \gamma_{p}=\gamma, \\
\frac{\partial \gamma}{\partial k}=\frac{\partial\left(\gamma_{e}+\xi \gamma_{p}\right)}{\partial k}=0, \quad k=\sqrt{\frac{\rho C_{\phi}}{\varepsilon_{0}}} \\
(p=100 \mathrm{kPa}-\text { atmospheric pressure }),(30)
\end{gathered}
$$

where $\gamma_{e}=\int_{0}^{h} w_{e} d x$ is electric component of surface energy (SE); $\gamma_{p}=\int_{0}^{h} w_{p} d x$ is mechanical (elastic) component of $\mathrm{SE} ; w_{e}=\frac{\varepsilon_{0}}{2}\left(\frac{\partial \Psi}{\partial x}\right)^{2}$ and $w_{p}=\frac{\sigma_{x x}\left(\sigma_{x x}-4 v \sigma_{y y}\right)}{2 E}+\frac{(1-v) \sigma_{y y}^{2}}{E} \quad$ are

density electrical and mechanical components of SE $[14,17,18,21] ; h$ is effective thickness of the surface layer; $E=G \frac{3 K+4 G}{3 K+G}$ is longitudinal elastic modulus (Young's); $v=\frac{3 K-2 G}{2(3 K+G)}$ is Poisson's ratio [17, 14]; $k$ is variational parameter (it's variation parameter in equation (29) [7.28 6.26]), (27) - the definition of surface tension [4, 25-27]; (28) is surface energy $\mathrm{y}$ in the form of two components $\gamma=\gamma_{\mathrm{e}}+\gamma_{d f t}$ it's similar to [5-7]: the first component is electrostatical $\gamma_{e}$; the second one $\gamma_{d f t}$ are kinetic, exchange, correlation components and energy of electron gas inhomogeneity (based of density functional theory (DFT)). In (28) $\gamma_{p}$ are expressed through mechanical stress $\sigma_{x x}, \sigma_{y y}$ and material data $E$ and $v[16,17,20]$.

For our approach:

$$
\gamma_{d f t}=\zeta \gamma_{p}
$$


where $\zeta$ is material data. Paramiter $\zeta$ is coming out:

$$
\xi=\left(\frac{\partial \gamma}{\partial \gamma_{p}}\right)_{\gamma_{e}=c o n s t}
$$

The potential $\varphi(25)$ and stress $\sigma_{x x}, \sigma_{y y}(26)$ are substituended in (27)-(30). The paramiters $k$, $\beta, \zeta, h$ and $\Phi_{0}$ of material (metal), it's surface is contacting with inert gas environment, are evaluated after surface tension $\sigma_{h}$, surface energy $\gamma$ and material data $E_{F}, k_{F}, E_{V}^{h}, W_{e}, E$, $\gamma$ are specified. These parameters are necessary in order to determine the energy characteristics of interfacial layers (particularly, on the interfase of "metal - insulator"). Similar characteristics $k, \beta, \zeta, h, Z_{C 0}$ of dielectric (semiconductor), which is in contact with an inert gas environment, are determined. The difference is that instead of considering free charges, the electrical charges caused by polarization $\omega_{C}$ are considered (they can be expressed in terms of the dipole moments) and polarization potentials $Z_{C}$. Those polarized charges are determined by increasing work of bound electric charge per unit mass of the appropriate phase of insulator or semiconductor [19, 20, 29].

\subsection{Thermodynamic and adhesive nanolayer parameters on the interface of "metal-insulator"}

The thermodynamic and adhesive nanolayer parameters of interface on "metal $-\mathrm{Al}_{2} \mathrm{O}_{3}$ dielectric coating" are determined in two stages. For the first phase, based on approach of surface physicists of metals on the interface with inert gas environment (air), the physical characteristics of materials (FCM) are determined based on equation class (11) and (12). For the second, the variation of FCM, under transition from "metal-air" to "dielectric-air" of contacting materials of "metal-insulator" (metal - coating), must be found. Then, we solves contact problem and interface energy paramiters (interfacial energy $\gamma_{i n t}$, interfacial tension oint, adhesive binding energy $\gamma_{a d}$, work of adhesion Aad, and other), which characterize the interfacial area and the functional properties of metalcoating are determined.

\subsubsection{The determination of interphase energy and tension}

The surface layer between the metal $(x>0)$ and coating $(x<0)$ is consider at the Cartesian coordinates $x, y$. The interfacial tension $\gamma_{\text {int }}$, interfacial energy oint, energy of adhesive bonds $\gamma_{\mathrm{Ad}}$ and work of adhesion $\mathrm{A}_{\mathrm{Ad}}$ at the interface of "metal - cover" are evaluated in same way as in $[16,19,28,30]$ :

$$
\begin{gathered}
\gamma_{\mathrm{int}}=\gamma_{m e}+\xi_{m} \gamma_{m p} ; \\
\gamma_{m e}=\int_{-H_{1}}^{H_{2}} w_{e} d x ; \quad \gamma_{m p}=\int_{-H_{1}}^{H_{2}} w_{p} d x ; \\
\sigma_{\mathrm{int}}=\int_{-H_{1}}^{H_{2}} \sigma_{y y} d x
\end{gathered}
$$

$\gamma_{A d}=\gamma+\gamma_{P}-\gamma_{\mathrm{int}} ; \quad A_{A d}=\sigma_{h}+\sigma_{P}-\sigma_{\mathrm{int}}$.

where $\zeta_{m}$ - the ratio of surface energy components on the interface of "metal-covering"; $\gamma_{m e}$, $\gamma_{m e c h}=\zeta_{m} \gamma_{m p}$ are electrical and mechanical (elastic) components of interfacial energy, respectively; $\mathrm{H}_{1}+\mathrm{H}_{2}$ is an effective thiknes of interface layer $\left(-H_{1}<x<H_{2}\right) ; \sigma_{P}$ and $\gamma_{\mathrm{P}}$ are surface tention and energy of surface covering (insulator or semiconductor) on the interface of inert gas environment (IGI) (or physical vacuum). Physical paramiters of equations (33) and (34), and their changes in the processes taking place under the influence of external factors (for example, during corrosion of metal) are determined based on information which were taken from mathematical model [1-3].

The equations of equilibrium of transition (interfacial) layer and the ratio of theoretical boundaries, which limit the area of interfacial layer (with $x=H_{1}$ in the metal and $x=-H_{2}$ in the coating) are presented just as in (29) and (30):

$$
\begin{gathered}
\frac{\partial \gamma_{\text {int }}}{\partial k_{m}}=0 ; \sigma_{y y 1}+p=0 \quad\left(x=H_{1}\right) ; \\
\sigma_{y y 2}+p=0 \quad\left(x=-H_{2}\right) ;
\end{gathered}
$$

where $k_{m}=\sqrt{\rho_{m} C_{m \phi} / \varepsilon_{0}}$ is variational parameter of electric charge distribution in the metal DEL; $\rho_{m}$ is density material of interfacial layer

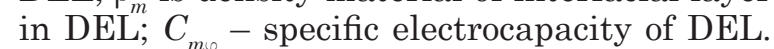
Herewith, lattice ions into consideration were not taken. The lattice is variated by uniform positive background (homogeneous electron background model, or "Jellium" model)) [8].

If the value of surface tension $\sigma_{h}$ and energy $\gamma$ of contacting intarfaces are known than the dimensionless parameters $\zeta_{m}$, the effective thickness $\mathrm{H}_{1}+\mathrm{H}_{2}$ of interfacial layer, electrocapacity $C_{m}$ of DEL, contact potential difference $\Delta \Psi$, energy parameters of interfacial layer and the electric charge of the surface phase $\Omega$ (it's charge on the plate of the capacitor, which were created as a result of electric charges redistribution in metal DEL) can be calculated with equations (33)-(35).

The state parameter $\Omega$ of surface phase for semi-infinite metal bodies, which were in con- 
Table 1. Physical parameters of metals $\mathrm{Ag}, \mathrm{Au}, \mathrm{Cu}, \mathrm{Fe}$ and dielectric $\mathrm{Al}_{2} \mathrm{O}_{3}$, which are in state equation (11) and (12).

\begin{tabular}{|c|c|c|c|c|c|}
\hline \multirow{2}{*}{$\begin{array}{c}\text { Physical } \\
\text { paramiter }\end{array}$} & \multicolumn{5}{|c|}{ Materials } \\
\cline { 2 - 6 } & $\mathrm{Au}$ & $\mathrm{Ag}$ & $\mathrm{Cu}$ & $\mathrm{Fe}$ & $\mathrm{Al}_{2} \mathrm{O}_{3}$ \\
\hline$\Phi_{0}, \mathrm{~V}$ & 4,96 & 4,344 & 4,706 & 4,503 & - \\
\hline$Z_{0}, \mathrm{~V}$ & - & - & - & - & 3,117 \\
\hline$\zeta$ & 0,119 & 0,0246 & 0,2481 & 0,552 & 19,52 \\
\hline $\mathrm{b}, \mathrm{V}^{-1}$ & 0,233 & 0,6083 & 0,2376 & 0,237 & 0,0176 \\
\hline $\mathrm{k}, \mathrm{m}^{-1}$ & $1,236 \cdot 10^{10}$ & $1,317 \cdot 10^{10}$ & $1,50 \cdot 10^{10}$ & $2,15 \cdot 10^{10}$ & $0,867 \cdot 10^{10}$ \\
\hline$\gamma_{\rho}, \mathrm{J}^{-2} \mathrm{~m}^{-2}$ & 1,333 & 1,0857 & 1,513 & 2,085 & 0,627 \\
\hline$\zeta \gamma_{p}, \mathrm{~J}^{-2}$ & 0,685 & 0,466 & 0,827 & 1,186 & 0,342 \\
\hline$\Omega, \mathrm{C} \cdot \mathrm{m}^{-2}$ & 0,382 & 0,3557 & 0,448 & 0,631 & 0,219 \\
\hline$h, \mathrm{~nm}$ & 1,065 & 1,058 & 0,901 & 0,645 & 1,324 \\
\hline$C, \mathrm{mF} \cdot \mathrm{m}^{-2}$ & 54,69 & 58,28 & 66,37 & 95,26 & 38,37 \\
\hline$\Delta \Psi, \mathrm{V}$ & 6,983 & 6,104 & 6,751 & 6,616 & 5,715 \\
\hline$d_{\zeta}=2 / \mathrm{k}, \mathrm{nm}$ & 0,162 & 0,152 & 0,133 & 0,093 & 0,231 \\
\hline$P_{e}$ & 2,54 & 1,93 & 1,9 & 1,83 & - \\
\hline
\end{tabular}

tact with not conductive inert gas environment with shift $\mathrm{Z}_{\mathrm{b}}$ is defined as follows:

$$
\Omega=\Omega_{1}=\int_{Z_{B}}^{\infty} \omega \cdot d x ; \quad\left[\Omega_{2}=\int_{-Z_{B}}^{-\infty} \omega \cdot d x\right] \text {; }
$$

where $x$ is a coordinate, perpendicular to the solid surface, with the starting point on the interface with the external environment; $x<0$ is a conductive body region; $x>0$ is an external environment (such as air or solid body(covering)); $x=Z_{B}$ is a distance from the body interface to the middle surface of electrical double layer (on the interface of "metal - air"); $\omega=\omega(x)$ is density of metal conductive electron; $\Omega_{1}, \Omega_{2}$ are surface charge densites of first and second capacitor plates of appropriate DEL $\left(\mathrm{C} / \mathrm{m}^{2}\right)$.

\subsubsection{Boundary conditions}

Let us define boundary (contact) conditions for electrical and mechanical fields at the interface between medias (at $x=0$ ). Those conditions is characterizing two DEL's, one of which is in metal, and the second is in dielectric coating [15, 17-20, 22, 26, 28,]:

$$
\begin{gathered}
E_{\tau 1}=E_{\tau 2} ; \quad D_{x 1}-D_{x 2}=\Omega+\Omega_{P} ; \\
\Omega_{P}=P_{x 1}-P_{x 2} ; \\
j_{x 1}=j_{x 2} ; \quad \sigma_{x x 1}=\sigma_{x x 2} ; \quad \sigma_{y y 1}=\sigma_{y y 2} ; \\
\vec{u}_{1}=\vec{u}_{2},
\end{gathered}
$$

where $\sigma_{x x i}, \quad \sigma_{y y i}$ is normal stresses $(i=1,2)$; $\vec{u}_{i}$ is a displasment; $j_{x i}$ is electric currents along the normal to the interface of environments; $E_{\tau i}$ is tangential component of the electric field; $D_{x i}, P_{x i}$ are vectors components of electric field and polarization, directed along the normal to the interface of environments $(x=0) ; \Omega_{P}$ is surface density of bouded inter- facial charges of dielectric. It should be noted that metal DEL is created by conduction electrons but in insulator by bound electric charges by dipoles. These two tipes of DEL is simulated by capacitors connected in series.

$$
\text { 3. "Metal }-\mathrm{Al}_{2} \mathrm{O}_{3} \text { " data . }
$$

\subsection{The parameters of DEL and energy} characteristics of interfacial layers of "metal (insulator) - inert gas" environment.

To calculate the physical properties of materials, such us: electrocapacity $C$, effective thickness $d_{\zeta}$ of DEL, density of interfacial free charge $\Omega$ or bounded charge $\Omega_{p}$ at the interface of "metal - coating", MHEP, $\mathrm{Z}_{0}$ in state equations, the known numerical values of physical parameters $E, v, \rho, K, G, E_{F}, E_{V}, W_{e}, \gamma, \sigma_{h}$ for iron, gold, silver, copper and dielectric $\left(\mathrm{Al}_{2} \mathrm{O}_{3}\right)[2,4,6-8,12,13,19$, 20, 25, 26-28, 31-33] were used ( Tabl 1.).

Where $Z_{0}$ is modified potential of bound charges on $\mathrm{Al}_{2} \mathrm{O}_{3} ; P_{e}$ is electronegativity; $\omega_{p}$ is density of free and bound charges per mass unit; $e=\left(e_{x r}+e_{y y}+e_{z z}\right) / 3$ is first invariant of strain tensor; $z_{p}=Z-Z_{0}$ is deviation of modified $Z$ potential of bounded electric charges at dielectric; $\Delta \psi$ is contact potential difference of DEL; $\beta_{p}$ for $\mathrm{Al}_{2} \mathrm{O}_{3}$ can be found from state equation like (12)

$$
\beta_{p}=\left.\frac{3(1+v)}{E} \cdot \frac{\partial \omega_{p}}{\partial e}\right|_{z_{p}=\text { const }} .
$$

For "metal - inert gas environment" we can write $[19,21]$ :

$$
\begin{aligned}
& \gamma_{e}=(\Omega)^{2} /(2 \cdot C)=C(\Delta \psi)^{2} / 2, \\
& C=\varepsilon_{0} \cdot k / 2, \quad d_{\xi}=2 / k
\end{aligned}
$$

For “metal - insulator" we can write (38): 
V. M. Yuzevych et al. / Thermodynamic and adhesive parameters ...

Table 2. Physical characteristics of the metal ( $\mathrm{Ag}, \mathrm{Au}, \mathrm{Cu}, \mathrm{Fe})-\mathrm{Al}_{2} \mathrm{O}_{3}$.

\begin{tabular}{|c|c|c|c|c|}
\hline \multirow{2}{*}{$\begin{array}{c}\text { Physical } \\
\text { paramiters }\end{array}$} & \multicolumn{4}{|c|}{ Materials } \\
\cline { 2 - 5 } & $\mathrm{Ag}-\mathrm{Al}_{2} \mathrm{O}_{3}$ & $\mathrm{Cu}-\mathrm{Al}_{2} \mathrm{O}_{3}$ & $\mathrm{Au}-\mathrm{Al}_{2} \mathrm{O}_{3}$ & $\mathrm{Fe}-\mathrm{Al}_{2} \mathrm{O}_{3}$ \\
\hline$\gamma_{i n t}, \mathrm{~J} \cdot \mathrm{m}^{-2}[2]$ & 0,888 & 1,039 & 1,140 & 1,375 \\
\hline$\sigma_{i n t}, \mathrm{~N} \cdot \mathrm{m}^{-1}$ & 0,765 & 0,893 & 0,994 & 0,841 \\
\hline$\gamma_{m e}, \mathrm{~J} \cdot \mathrm{m}^{-2}$ & 0,555 & 0,645 & 0,747 & 2,865 \\
\hline$\gamma_{A d}, \mathrm{~J} \cdot \mathrm{m}^{-2}$ & 1,441 & 1,469 & 1,687 & 1,452 \\
\hline$\zeta_{m}$ & 0,553 & 0,814 & 0,122 & 0,233 \\
\hline$b_{m}, \mathrm{~V}^{-1}$ & 0,243 & 0,202 & 0,329 & $2,914 \cdot 10^{10}$ \\
\hline$k_{m}, \mathrm{~m}^{-1}$ & $1,647 \cdot 10^{10}$ & $1,993 \cdot 10^{10}$ & $1,500 \cdot 10^{10}$ & 0,466 \\
\hline$\Omega_{\mathrm{m}}, \mathrm{C} \cdot \mathrm{m}^{-2}$ & 0,285 & 0,337 & 0,315 & 128,9 \\
\hline$C_{m},{\mathrm{mF} \cdot \mathrm{m}^{-2}}_{\Delta \Psi_{m}, \mathrm{~V}}$ & 72,89 & 88,19 & 66,36 & 3,612 \\
\hline \hline
\end{tabular}

$$
\begin{aligned}
& \gamma_{m p}=\left(\Omega_{m}\right)^{2} /\left(2 \cdot C_{m}\right)=C_{m}\left(\Delta \psi_{m}\right)^{2} / 2, \\
& C_{m}=\varepsilon_{0} \cdot k_{m} / 2, \quad d_{\xi m}=2 / k_{m}
\end{aligned}
$$

where $C_{m}$ and $Q_{m}$ are electrocapacity and interface charge of DEL (MDEL); $\Delta \psi_{m}$ is contact potential difference of MDEL; $d_{m}$ is effective thickness of MDEL; $k_{\mathrm{m}}$ is MDEL variational parameters.

Obtained experimental and theoretical data shows: 1) significant difference between physical parameters of studied electrical double layer of metal and dielectric, such as corrosion-proof $(\mathrm{Au}, \mathrm{Ag}, \mathrm{Cu})$ and noncorrosine-proof $(\mathrm{Fe})$ metals; 2) copper is differ by paramiters $\left(\zeta, k, \gamma_{e}\right.$, $\left.\zeta \gamma_{p}, \Omega, h, \mathrm{C}, \Delta \Psi, d_{\zeta}\right)$ from other corrosion-proof metals. As we know, it also has anomalous properties such as: large diffusion coefficient, tendency to twinning; high viscosity, plasticity and high electrical conductivity.

So, quantitative values of these parameters can be used in the planning of nanotechnology and quantitative description of surface properties and interphase interactions of metals and dielectrics.

\subsection{The calculation of DEL parameter} in "metal-dielectrics"

Physical situation on the interface of two environment in "metal-insulator" is substantially differ from the described above "metalinert environment". Therefore, to obtain energy parameters, we need to formulate the contact problem, which include conditions for the electrochemical potential, currents and diffusion tensor mechanical stresses. Base on numerical data of physical values of interfacial energy in "metal - insulator $\mathrm{Al}_{2} \mathrm{O}$ ", by use of density functional theory (DFT) [2] for "metal - covering (insulator - $\mathrm{Al}_{2} \mathrm{O}_{3}$ ), a number of physical characteristics were calculated (Tabl. 2).

Relative changes of $\gamma, k, \Omega, C, \Psi$ parameters for metals ( $\mathrm{Ag}, \mathrm{Au}, \mathrm{Cu}, \mathrm{Fe}$ ) under the influence of $\mathrm{Al}_{2} \mathrm{O}_{3}$ cover were shown in Table 3 . As we can see, the changes of variational parameter $k$ and capacity $C$ are similar.

As we can see, quantitative values of energy parameters of interfacial interactions $\left(\gamma_{\text {int }}, \sigma_{i n t}\right.$, $\left.\gamma_{e}, \gamma_{\mathrm{Ad}}\right)$ in $\mathrm{Fe}-\mathrm{Al}_{2} \mathrm{O}_{3}$ are significantly higher than the studied metals $\mathrm{Ag}, \mathrm{Cu}, \mathrm{Au}$ (Table 2). This shows a greater adherence and higher levels of mechanical stress on the boundary of $\mathrm{Fe} /$ $\mathrm{Al}_{2} \mathrm{O}_{3}$. That is why, the prospects for practical use of $\mathrm{Al}_{2} \mathrm{O}_{3}$ as a resistant protective and anti corrosive coating for $\mathrm{Fe}$ is coming out.

A high value of electric component $\gamma_{e}$ and specific electrical charge $\Omega_{m}$ on the interface of DEL in $\mathrm{Fe}-\mathrm{Al}_{2} \mathrm{O}_{3}$ are testify the dipoleelectronic nature of concentrated electric field there. That's also confirm high value of specific electrocapacity $C_{m}$. Which is caused by a specific electronic configuration of $\mathrm{Fe}$ atoms on research of $\mathrm{Ag}, \mathrm{Cu}, \mathrm{Au}$. Thus, the formation of interactions on "insulator-metal" interface the electronic configuration of metal is important. 
Table 3. Relative changes of $\gamma, k, \Omega, C, \psi$ under influence of covering

\begin{tabular}{|c|c|c|c|c|}
\hline & $\mathrm{Ag}-\mathrm{Al}_{2} \mathrm{O}_{3}$ & $\mathrm{Cu}-\mathrm{Al}_{2} \mathrm{O}_{3}$ & $\mathrm{Au}-\mathrm{Al}_{2} \mathrm{O}_{3}$ & $\mathrm{Fe}-\mathrm{Al}_{2} \mathrm{O}_{3}$ \\
\hline$\left(\gamma-\gamma_{m}\right) / \gamma$ & 0,606 & 0,556 & 0,435 & 0,580 \\
\hline$\left(k-k_{m}\right) / k$ & $-0,251$ & $-0,329$ & $-0,213$ & $-0,353$ \\
\hline$\left(\Omega-\Omega_{m}\right) / \Omega$ & 0,200 & 0,248 & 0,176 & 0,261 \\
\hline$\left(C-C_{m}\right) / C$ & $-0,251$ & $-0,329$ & $-0,213$ & $-0,354$ \\
\hline$\left(\Delta \psi-\Delta \psi_{m}\right) / \Delta \psi$ & 0,361 & 0,434 & 0,321 & 0,454 \\
\hline
\end{tabular}

\subsection{Energy characteristics size} dependence of ultrafine compositions.

Let's consider a composite cover. It's consist of dielectric matrix containing ultradispersed strengthening particles. Such system is composite cover of $\mathrm{Al}_{2} \mathrm{O}_{3}+5$ vol. \% SiC, it's strengthened with ultradispersed particles of $\mathrm{SiC}$, which leads to an increase in hardness compared with $\mathrm{Al}_{2} \mathrm{O}_{3}$ to $20 \%$ [4].

Let's use experimentally established correlation between surface energy $\gamma$ and hardness $M_{s}[16,19,32,33,34,35]$ :

$$
\gamma_{2}=\gamma_{1} \cdot\left(M_{t 2} / M_{t 1}\right)^{\zeta}
$$

where $M_{t 1}$ and $M_{t 2}$ are materials hardness in two states $S_{1}$ end $S_{2}$, two values of surface energy $\gamma_{1}$ and $\gamma_{2}$ are respond respectively; $\zeta$ is empirical dimensionless parameter, which takes a certain value in the range $[1,2]$.

After analysis of equation (40) we have found that, in particular, for states $S_{1}(\zeta=1)$ and $S_{2}$ $(\kappa=1,5)$ respective values of surface energy $\gamma_{1}=1,27 \mathrm{~J} / \mathrm{m}^{2}$ i $\gamma_{2}=1,428 \mathrm{~J} / \mathrm{m}^{2}\left(\gamma_{1} / \gamma_{0}=1,067\right.$; $\left.\gamma_{2} / \gamma_{0}=1,2\right)$ are responded. For initial state the value $\gamma_{0}=0,969$ Дж/ $/ \mathrm{M}^{2}$ is corresponds.

After calculations, the changes in physical parameters corresponding to growth of surface energy of the composite cover on $20 \%$ for $\zeta=1,5$ (40) (state $S_{2}$ ) compare with initial state $S_{0}$ were found.

To evaluate the changes of energy and other parameters at the interfacial surface between metal and covering we use next relationships:

$$
\begin{aligned}
& \delta \gamma_{m}=2 \frac{\gamma_{m 2}-\gamma_{m 1}}{\gamma_{m 2}+\gamma_{m 1}}, \quad \delta \gamma_{E}=2 \frac{\gamma_{E 2}-\gamma_{E 1}}{\gamma_{E 2}+\gamma_{E 1}}, \\
& \delta C_{m}=2 \frac{C_{m 2}-C_{m 1}}{C_{m 2}+C_{m 1}}, \ldots, \quad \delta d_{\xi}=2 \frac{d_{\xi 2}-d_{\xi 1}}{d_{\xi 2}+d_{\xi 1}}
\end{aligned}
$$

After comparing the states $S_{0}$ and $S_{2}$ (Fe$\mathrm{Al}_{2} \mathrm{O}_{3}$ ), which correspond to strengthen the composite cover to $20 \%$ and contact problem solving the physical parameters for $\mathrm{Fe}-\mathrm{Al}_{2} \mathrm{O}_{3}$ (SiC) are calculated. Based on those equations we have got:

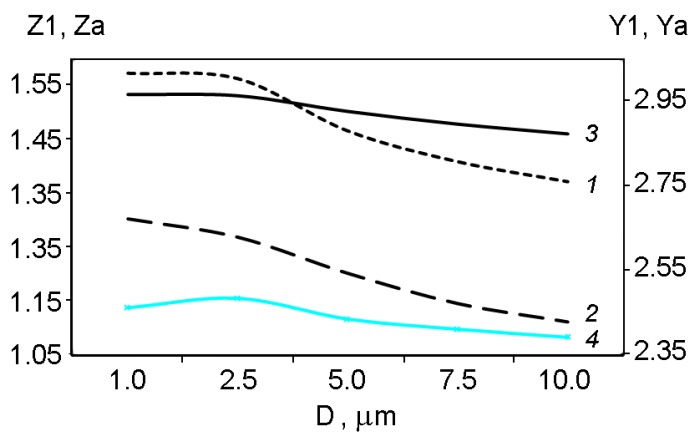

Fig. 1. Energy parameters of interfacial layer of " $(\mathrm{Fe})$ metal - insulator $\mathrm{Al}_{2} \mathrm{O}_{3}$ " as a function of diameter $D$ of ultradispersed $\mathrm{SiC}$ particles $\left(1-Z_{1}=\gamma_{i n t}=f(D), 2-Z_{\alpha}=\sigma_{i n t}=f(D), 3-Y_{1}=\right.$ $\gamma_{A d}=f(D)$ and $\left.4-Y_{a}=A_{A d}^{a}=f(D)\right)$.

$$
\begin{aligned}
\delta \gamma_{m}= & 0,149 ; \delta \gamma_{E}=0,151 ; \delta C_{m}=-0,0312 ; \\
\delta \sigma_{m}= & 0,149 ; \delta Q_{m}=0,0602 ; \delta k_{m}=-0,0312 ; \\
& \delta d_{\zeta}=0,0317 ; \delta(\Delta \Psi)=0,0913 .
\end{aligned}
$$

For the range $\zeta=1,0 \div 1,5$, the reinforced cover from state $S_{1}$ to state $S_{2}$ similarly as in the previous case (42) were calculated:

$$
\begin{gathered}
\delta \gamma_{m}=0,0974 ; \delta \sigma_{m}=0,0986 ; \delta \gamma_{E}=0,0989 \\
\delta C_{m}=-0,0202 ; \delta Q_{m}=0,0395 ; \delta k_{m}=-0,0202 ; \\
\delta d_{\zeta}=0,0206 ; \delta(\Delta \Psi)=0,0596
\end{gathered}
$$

The results of energy parameters calculations for " $(\mathrm{Fe})-\mathrm{Al}_{2} \mathrm{O}_{3}$ " as a function of diameter $\mathrm{D}$ of ultradispersed $\mathrm{SiC}$ particles (for range $D=1 \div 10 \mu \mathrm{m})$ are shown in Fig. 1 .

As we can see, $\gamma_{A d}$ and $A_{A d}$ parameters, under variation of the diameter of ultradispersed $\mathrm{SiC}$ particles, are changes only within $5 \div 6 \%$. The dependency of $A_{A d}=f(D)$ has maximum at $D=2,5 \mu \mathrm{m}$. Surface tension $\sigma_{h}$ and energy $\mathrm{Y}$ for $\mathrm{Al}_{2} \mathrm{O}_{3}$ are changed in $30 \%$. Interfacial energy parameters $\gamma_{i n t}$ and $\sigma_{i n t}$ are changed in the range $15 \div 17 \%$ and increases with decreasing of particle ultradispersed $\mathrm{SiC}$ diameter.

\section{Conclusions}

The method of evaluation of thermodynamic and adhesive parameters of interphase nanolayers in "metal - insulator" system with mac- 
roscopic techniques of surface physics and nonequilibrium thermodynamics were proposed. The parameters of interface interaction (interface energy, tension, density of electrical charges, specific electrocapacity, electrical components of interfacial energy) for interface "metal $(\mathrm{Ag}, \mathrm{Au}, \mathrm{Cu}, \mathrm{Fe})-\mathrm{Al}_{2} \mathrm{O}_{3}$ ” were calculated.

The electronic configuration of interacting metal is determining factor in the formation of interfacial interactions in "insulator - metal" system.

Size dependences of energy parameters of interface interaction in "metal - composite covering" which consist of dielectric matrix with strengthen ultradispersed particles $\left(\mathrm{Al}_{2} \mathrm{O}_{3}+5\right.$ vol. $\% \mathrm{SiC}$ is strengthen by ultradispersed $\mathrm{SiC}$ particles) were found.

It were shown that increase of surface energy of coating by $20 \%$ (by adding to $\mathrm{Al}_{2} \mathrm{O}_{3} 5 \%$ of $\mathrm{SiC}$ ) that increase the interface tension $\sigma_{m}$, energy $\gamma_{m}$ and electric component of interfacial energy by $15 \%$, specific surface charge of double electric layer (DEL) by $6 \%$, reducing of specific electro capacity of DEL and radiational parameter $k$, which characterize the distribution of electric charge by $3,1 \%$.

\section{Reference}

1. V. A. Sozajev, Techn., Phys. Lett., 31, 27, 2005

2. E. Burello, A. P. Worth, Nanotoxicol., 5, 228, 2011.

3. D. W. Stollberg; J. M. Hampikian, L. Riester, et al, Mater. Scie. Eng. A, 359, 112, 2003.

4. S. S. Teske, C. S. Detweiler, Int. J. Environ. Res. Public Health, 12, 1112, 2015. doi:10.3390/ijerph120201112.

5. B.Missol, The Surface Energy of the Phase Separation in Metals. -M .: Metallurgy, 1978. [ 6. N. C. Lang, W. Kohn, Phys. Rev. B, 1, 35551970.

7. M. B. Partenskii, Sov. Phys. Usp. 22, 330,1979.

8. V. N. Yuzevich, B. P. Koman, Fiz. Tverd. Tela, 56, 895, 2014.

9. A. S. Peterson, Condensed Matter Physics Commons. Retrospective Theses and Dissertations. Paper 6938. - Ames, Iowa, U.S., 1981. - 73 p.

10. В. Р. Комаn, V. N. Yuzevich, Fiz. Tverd. Tela, 54, 1335, 2012.

11. V. N. Yuzevich, B. Р. Комan, Fiz. Tverd. Tela, 56, 895, 2014].

12. Stojek Z. The Electrical Double Layer and its Structure. Chapter I.1. / Electroanalytical Methods Guide to Experiments and Applications // Ed F. Scholz. 2005. XII, P. 1-8.

13. Herring C, Surface Tension as a Motivation for Sintering, in Phys. Powder Metal., ed. W.E. Kingston, McGraw-Hill, New York, 1951, p. 143.

14. R. Shuttleworth, Proc. Phys. Soc., A, 63, 444 1950.

15. R. C. Cammarata, Progr. Surf. Sci., 46, 1, 1994.
16. B. P. Koman, V.M. Yuzevich, J. Nano- Electron. Phys., 7, 04059, 2015.

17. Timoshenko S. P., Goodier J. N.. Theory of Elasticity. -New York - Toronto -London: McGrawHill Book Company, 1951, 519 p.

18. L. Dorfmann. Modeling Nonlinear Electroelastic Materials / Mechanics and Electrodynamics of Magneto- and Electroelastic Materials. Editors: R. W. Ogden, D. J. Steigmann, Publisher: Springer, 527, 57, 2011.

19. P. Soprunjuk, V.M. Yuzevych. The diagnostic of materials and environments. Energy characteristics of the surface layers., Lviv, PMI them. Karpenko NAS of Ukraine, "SPOL". p. 292, 2005

20. S. R. de Groot, P. Mazur. Non-Equilibrium Thermodynamics. North-Holland Publishing Company, Amsterdam, 1962.

21. Maugin G. A. Electromagnetics in Deformable Solids / Mechanics and Electrodynamics of Magneto- and Electroelastic Materials. Ed. R. W. Ogden, D. J. Steigmann, Publisher: Springer. 527, $57,2011$.

22. A. I. Rusanov Surface thermodynamics revisited / Surface Science Reports. Elsevier. Editor-inChief: Charles T. Campbell., 58, 111, 2005.

23. Banasiak J., Lachowicz M. Methods of Small Parameter in Mathematical Biology. Modeling and Simulation in Science, Engineering and Technology. - Springer, Birkhäuser, p. 272, 2014.

24. Karlint S. and McGregor J. Application of Method of Small Parameters to Multi-Niche Population Genetic Models (Stanford University), Theoretical population in biology. 3, 186, 1972.

25. Solid State Surface Science, Vol. 1, edited by M. Green, Marcel Dekker, New York, NY, USA, 1969.

26. N. Eustathopoulus, Joud J.-C. Current Topics Mater. Sci., 4, 281, 1980.

27. R. G. Linford, Solid State Surface Sci., 2, 1, 1973.

28. J. R. Smith, Phys. Rev., 181, 522, 1969.

29. Martinsen O. G., Grimnes S., Schwan H. P., Encyclopedia of Surface and Colloid Science. New York. Ed. by M. Dekker, P. 2643, 2002

30. A. W. Adamson, A. P. Gast, Physical Chemistry of Surfaces / 6th Edition. Department of Chemistry, University of Southern California Los Angeles, California. 1997. A Wiley-Interscience Publication, John Wiley and Sons, Inc. New York, Singapore, Toronto.

31. Charles Kittel. Introduction to Solid State Physics, 8th Ed., 2004.

32. M. Alden, S. Mirbt, H. L. Skriver, Phys. Rev. B, 46, 6303,1992.

33. S. K. Rhee S. K. J. Amer. Ceram. Soc. 55, 300 1972.

34. V.D. Kuznetsov. The Surface Energy of solids. M.: Hostehyzdat, 1954. - 220 p. (in Russian)

35. R. V. Armstrong, Materials, 4, 1287, 2011. 